\title{
Migration Towards Broadband PPDR Networks
}

\author{
Henryk Gierszal* $^{*}$, Piotr Tyczka ${ }^{\dagger}$, Karina Pawlina ${ }^{\dagger}$, Krzysztof Romanowski $^{\dagger}$, Damien Lavaux ${ }^{\ddagger}$, \\ John Burns ${ }^{\S}$, Val Jervis ${ }^{\S}$, Luis Teixeira ${ }^{\Uparrow}$, and Andre Oliveira \\ *Adam Mickiewicz University, Umultowska 85, 61-614 Poznań, Poland \\ Email: gierszal@amu.edu.pl \\ †ITTI Sp. z o.o., Rubież 46, 61-612 Poznań, Poland \\ Email: \{piotr.tyczka, karina.pawlina, krzysztof.romanowski\}@itti.com.pl \\ $\ddagger$ DSC Advanced Studies, Thales Communications \& Security SAS, Gennevilliers, France \\ Email: damien.lavaux@thalesgroup.com \\ $\S$ Plum Consulting, 10 Fitzroy Square, London, United Kingdom \\ Email: \{john.burns, val.jervis\} @ plumconsulting.co.uk \\ ฯTEKEVER, Rua da Leziria 1, 2510-080 Obidos, Portugal \\ Email: \{luis.teixeira, andre.oliveira $\} @$ tekever.com
}

\begin{abstract}
This paper presents a study on development and evolution of Public Protection and Disaster Relief (PPDR) communication networks in the perspective of the next 15-20 years. A need for modern, reliable mobile communications systems for PPDR offering a wide range of services, yet harmonized, is commonly recognized at both country and European level. There are therefore a number of activities in this area currently being undertaken. In this paper we discuss several technical aspects of migration of PPDR networks towards broadband systems and describe the most likely upgrade scenario based on an evaluation of migration costs.
\end{abstract}

\section{INTRODUCTION}

$\mathbf{P}$ UBLIC Protection and Disaster Relief (PPDR) is the general designation given to a range of public safety services: medical emergency services, police squads, fire brigades, etc. Secure and reliable wireless communication between personnel and sections of PPDR agencies, as well as between different PPDR agencies is a vital element of their successful operation and ensuring safety of PPDR staff both in routine and emergency situations. Another crucial challenge is to make these communications suitable for "media type" services, that are increasingly utilized over public mobile networks, to improve the range of information available to the PPDR end-users.

Nowadays PPDR organizations are facing the challenge of migrating from narrow- and even wideband Public Safety Communication (PSC) systems to broadband ones because different public services or utilities increasingly need broadband solutions, e.g. to transmit video streams from an incident scene to the headquarters or benefit from applications of augmented reality. Simple replacement of current network elements to broadband ones is not feasible because broadband transmission needs wider bandwidths that can only be allocated in higher frequency band. Also the adoption of higher frequencies will reduce the maximum range of cells and require additional

This work was supported by European Union in the framework of the FP7SEC-2012.5.2-1 program - project "Public Protection and Disaster Relief Transformation Center - PPDR-TC" (contract no. 313015). sites. In addition the broadband infrastructure will need to be upgraded so it can support the higher capacity required to support the higher bandwidth traffic and also the additional sites.

In this paper, based on work performed under the EC FP7 project "Public Protection and Disaster Relief - Transformation Center - PPDR-TC", we present a study on technical, business and organizational aspects of development and evolution of PPDR mobile communication networks. It takes into account the likely developments of wired and wireless communications networks over the next 15-20 years as well as the currently available technologies.

The paper is organized as follows. In Section II we present the PPDR requirements for future networks that result from their needs and available technologies. Section III describes the architecture of the future PPDR systems that meets both end-users requirements and possible business models. In Section IV the migration path towards broadband PPDR networks is proposed and discussed. Section $\mathrm{V}$ gives an example of expenditures for such a migration. Finally, Section VI contains conclusions.

\section{PPDR REQUIREMENTS}

Modern telecommunication networks have evolved as service-oriented infrastructure in order to meet end-users' requirements that in fact are related to different use-cases. Literature survey [1]-[3] and meetings with stakeholders led to the definition of eight typical communication scenarios:

- Communication Scenario A: between a central control station and field personnel at an incident location,

- Communication Scenario B: between PPDR vehicles and an incident location or control station,

- Communication Scenario C: between individuals at an incident location,

- Communication Scenario D: between different PPDR entities (e.g. police, fire, ambulance),

- Communication Scenario E: accessing information from the Internet or other external data sources (including 
corporate intranets),

- Communication Scenario F: communication in enclosed spaces (e.g. tunnels or basements),

- Communication Scenario G: communication with remote locations (e.g. mountains),

- Communication Scenario H: communication with or between machines (e.g. remotely controlled vehicles).

The above listed scenarios require different traffic volumes to be supported depending on the operational circumstances in which the PPDR agencies are involved. Three categories of operational activities were defined by end-users:

- Routine day-to-day activities - traffic volume is low or moderate (no network congestion observed),

- Major events - higher communication needs have to be provided as compared to routine day-to-day activities but the location and requirements are known in advance, therefore some planning can be done earlier,

- Major incidents or disasters - higher communication needs have to be available at very short notice and the location and requirements are not known in advance.

The bearer services (i.e. basic services for transport of information payloads) that may be required by PPDR users was another type of classification considered in the PPDR-TC project. On the basis of the opinions provided by end-users and other analysis [3, 4], the following five categories were identified:

- Voice,

- Narrowband (NB) Data (e.g. for messaging),

- Broadband (BB) Data (e.g. for sending or receiving images or large files, and for accessing databases),

- Video (similar to broadband data but likely to be more demanding in terms of latency),

- Use of repeater stations to extend coverage, e.g. into enclosed or remote areas.

Broadband services are also needed for video and challenging services.

Finally, a series of functionalities that should be provided by broadband PPDR networks was identified and grouped into six sets as shown in Table I. Voice services will always be required irrespectively of the other types of services available for PPDR. The throughput threshold used to distinguish between narrow- and broadband transmission was set at $384 \mathrm{kbps}$, however in many definitions it has been already increased to $1 \mathrm{Mbps}$ and recently even to 4 up to $25 \mathrm{Mbps}$ [5]. Broadband transmission is required by video services and other new potentially challenging services. Repeater (relay) services are linked with communication scenarios $F$ and $G$ discussed above. All services should be available within the whole PPDR network of, at least, national coverage.

PPDR organizations can use services listed in Table II for many applications identified in [6]. Many of them need broadband transmission but there are still plenty of applications for which narrowband transmission is sufficient.
Table I

REQUIRED FUNCTIONALITIES FOR BROADBAND PPDR NETWORKS

\begin{tabular}{|c|c|}
\hline Groups & Functionalities \\
\hline \multirow{9}{*}{$\begin{array}{l}\text { Voice } \\
\text { (common PPDR } \\
\text { voice services) }\end{array}$} & push-to-talk \\
\hline & private call \\
\hline & group call \\
\hline & emergency/priority call \\
\hline & call retention/busy queuing \\
\hline & direct mode operation \\
\hline & ambience listening \\
\hline & $\begin{array}{l}\text { voice over the Public Switched } \\
\text { Telephone Network (PTSN) }\end{array}$ \\
\hline & $\begin{array}{l}\text { area selection/Dynamic Group Number } \\
\text { Assignment (DGNA) }\end{array}$ \\
\hline \multirow{7}{*}{$\begin{array}{l}\text { Narrowband data } \\
\text { (data transmission } \\
\text { up to } 384 \mathrm{kbps} \text { ) }\end{array}$} & messaging and notifications \\
\hline & low resolution photos \\
\hline & automatic telemetrics \\
\hline & location-based information \\
\hline & mobile workspace applications \\
\hline & access to internal databases \\
\hline & access to external sources \\
\hline \multirow{7}{*}{$\begin{array}{l}\text { Broadband data } \\
\text { (data transmission } \\
\text { over } 384 \mathrm{kbps} \text { ) }\end{array}$} & rapid file transfer \\
\hline & high resolution photos \\
\hline & remote operations \\
\hline & $\begin{array}{l}\text { mapping with Geographic Information } \\
\text { System (GIS) layers }\end{array}$ \\
\hline & mobile workspace applications \\
\hline & access to internal databases \\
\hline & access to external sources \\
\hline \multirow{3}{*}{$\begin{array}{l}\text { Video } \\
\text { (data transmission } \\
\text { with tighter latency } \\
\text { and coding } \\
\text { requirements) }\end{array}$} & video transmission \\
\hline & video streaming \\
\hline & video call \\
\hline \multirow{3}{*}{$\begin{array}{l}\text { Transversal services } \\
\text { (extension of voice } \\
\text { and data capabilities } \\
\text { and performance) }\end{array}$} & extension of coverage \\
\hline & extension of availability \\
\hline & encryption tools \\
\hline \multirow{2}{*}{$\begin{array}{l}\text { Challenging services } \\
\text { (services enabled by } \\
\text { the next generation of } \\
\text { technologies) }\end{array}$} & proximity services \\
\hline & augmented reality \\
\hline
\end{tabular}

\section{ARChitecture of FUtURE PPDR Systems}

\section{A. Business Models}

Migration to broadband systems can be examined using different business models for which CAPital EXpenditures (CAPEX) and OPerational EXpenditures (OPEX) can be split in different proportions. Three approaches were identified in [7] and described in [8]:

1) dedicated networks - a PPDR organization builds its own network infrastructure, or the build is done by a commercial operator based on a turnkey contract. The new network can be operated by the PPDR organization or by a commercial operator;

2) commercial networks - commercial operator(s) use public network(s) operated in order to provide PPDR services with a required Quality of Service (QoS);

3) hybrid networks - any mix of the above.

It means that the business model finally adopted by a PPDR body will significantly affect the whole process of acquiring a new network. It includes technical, financial-economic, and organizational issues. The hybrid network seems the most 
Table II

LIST OF APPLICATIONS NEEDED BY PPDR

\begin{tabular}{|c|c|}
\hline ID & Applications \\
\hline$\overline{\mathrm{APP} 1}$ & $\begin{array}{l}\text { Automatic (Vehicle) Location System }(\mathrm{A}(\mathrm{V}) \mathrm{LS}) \text { data to } \\
\text { Command and Control Centre (CCC) }\end{array}$ \\
\hline APP2 & $\mathrm{A}(\mathrm{V}) \mathrm{LS}$ data return \\
\hline APP3 & Video from/to CCC for following and intervention \\
\hline APP4 & Low quality additional feeds \\
\hline APP5 & Video for fixed observation \\
\hline APP6 & High quality additional feeds \\
\hline APP7 & $\begin{array}{l}\text { Video on location (disaster or event area) to and from control } \\
\text { room - high quality }\end{array}$ \\
\hline$\overline{\text { APP8 }}$ & $\begin{array}{l}\text { Video on location (disaster or event area) to and from control } \\
\text { room - low quality }\end{array}$ \\
\hline APP9 & Video on location (disaster or event area) for local use \\
\hline$\overline{\mathrm{APP} 10}$ & Video conferencing operations \\
\hline APP11 & Non real time recorded video transmission \\
\hline APP12 & Photo broadcast \\
\hline APP13 & Photo to selected group (e.g., based on location) \\
\hline APP14 & $\begin{array}{l}\text { Personal Information Management (PIM) synchronization in } \\
\text { Personal Digital Assistant (PDA) }\end{array}$ \\
\hline$\overline{\text { APP15 }}$ & Mobile workspace (including public Internet) \\
\hline APP16 & $\begin{array}{l}\text { Incident information download (text and images) from CCC } \\
\text { to field units and netcentric working }\end{array}$ \\
\hline APP17 & Automatic Number Plate Recognition (ANPR) update hit list \\
\hline APP18 & Download maps with included information to field units \\
\hline APP19 & $\begin{array}{l}\text { Command \& control information including task management } \\
\text { and briefings }\end{array}$ \\
\hline$\overline{\mathrm{APP} 20}$ & $\begin{array}{l}\text { Incident information upload (text and images) to CCC and } \\
\text { netcentric working }\end{array}$ \\
\hline APP21 & Status information and location \\
\hline APP22 & $\begin{array}{l}\text { ANPR or speed control automatic upload to database } \\
\text { including pictures (temporally 'fixed' cameras and from } \\
\text { vehicles) }\end{array}$ \\
\hline APP23 & Forward scanned documents \\
\hline APP24 & Reporting including pictures, etc. \\
\hline APP25 & Upload maps and schemes with included information \\
\hline APP26 & Patient monitoring - snapshot to hospital \\
\hline APP27 & Patient monitoring - real time monitoring to hospital \\
\hline APP28 & $\begin{array}{l}\text { Monitoring status of security worker (drop detection, stress } \\
\text { level, carbon monoxide, etc.) }\end{array}$ \\
\hline APP29 & Operational database search (own and external) \\
\hline APP30 & Remote medical database services \\
\hline APP31 & ANPR checking number plate live on demand \\
\hline APP32 & Biometric (e.g., fingerprint) check \\
\hline APP33 & Cargo data \\
\hline APP34 & Crash Recovery System (asking information on the spot) \\
\hline APP35 & Crash Recovery System (update to vehicles from database) \\
\hline APP36 & Software update online \\
\hline APP37 & GIS maps updates \\
\hline APP38 & $\begin{array}{l}\text { Automatic telemetrics including remote controlled devices } \\
\text { and information from static sensors }\end{array}$ \\
\hline APP39 & $\begin{array}{l}\text { Hotspot on disaster or event area (e.g., in mobile } \\
\text { communication centre) }\end{array}$ \\
\hline$\overline{\mathrm{APP}} 40$ & $\begin{array}{l}\text { Front-office and back-office applications, form filling online } \\
\text { with back-office system, etc. }\end{array}$ \\
\hline APP41 & Alarming / paging \\
\hline APP42 & $\begin{array}{l}\text { Traffic management system: information on road situations } \\
\text { to units }\end{array}$ \\
\hline APP43 & Connectivity of abroad assigned force to local CCC \\
\hline$\overline{\mathrm{APP}} 44$ & $\begin{array}{l}\text { Unmanned Aircraft System (UAS) and Unmanned Ground } \\
\text { Vehicle (UGV) control applications }\end{array}$ \\
\hline APP45 & Sensors on site \\
\hline
\end{tabular}

promising approaches but also the most challenging because two (or even more) networks have to be integrated in order to provide services in a seamless and efficient way. Typically it involves the setting up as a PPDR Mobile Virtual Net- work Operator (MVNO) over a commercial network(s) [9]. It was also noticed in [10] that hybrid solutions involve both dedicated specialized and commercial networks. This hybrid approach combines existing PPDR networks (e.g., TETRA) with a phased move to a common LTE infrastructure. A hybrid solution is also discussed in [11] as the most economic strategy where the dedicated network is operated in areas with high density of population, and services in rural areas are provided by commercial network(s).

\section{B. System Architecture of Shared Radio Access Network}

In this approach a broadband Radio Access Network (RAN) is managed by a Commercial Mobile Network Operator (CMNO) who shares it with the PPDR agency. A PPDR organization owns its 3G/LTE core network. Such a network is used for voice and data. However, mission-critical voice and narrowband data services remain on the Professional Mobile Radio (PMR) network already used, e.g., TETRA. The own core network enables the PPDR operator to have full control of the PPDR users with respect to their subscriptions, service profiles and service portfolio.

The network architecture is shown in Fig. 1. There are three sub-networks:

- 3G operated by CMNO,

- 4G operated by CMNO,

- TETRA/TETRAPOL operated by PPDR agency.

There are also a few components operated by the MVNO that are needed to provide access to the network resources. MVNO is the PPDR agency or an operator delegated by PPDR agency. In this strategy there are many commitments that have to be met by the MVNO and CMNO.

CMNO's 3G network consists of:

- RAN that composes of:

- Node-B (NB) base stations,

- Radio Network Controllers (RNC),

- core network where the most important components are:

- Serving GPRS Support Node (SGSN),

- Gateway Mobile Switching Center (GMSC).

MVNO's 3G core network is composed of:

- for Circuit Switching (CS):

- Mobile Switching Center (MSC),

- Visited Location Register (VLR),

- Equipment Identity Register (EIR),

- GMSC,

- for Packet Switching (PS):

- Gateway GPRS Support Node (GGSN).

In 3G CS domain MVNO operates:

- CS GateWay (CS GW).

Common components for $3 \mathrm{G}$ CS and PS domains in the MVNO network are the following:

- Home Location Register (HLR),

- Short Messaging Service Center (SMS-C),

- Multimedia Message Service Center (MMS-C),

- Value-Added Service (VAS) platform. 


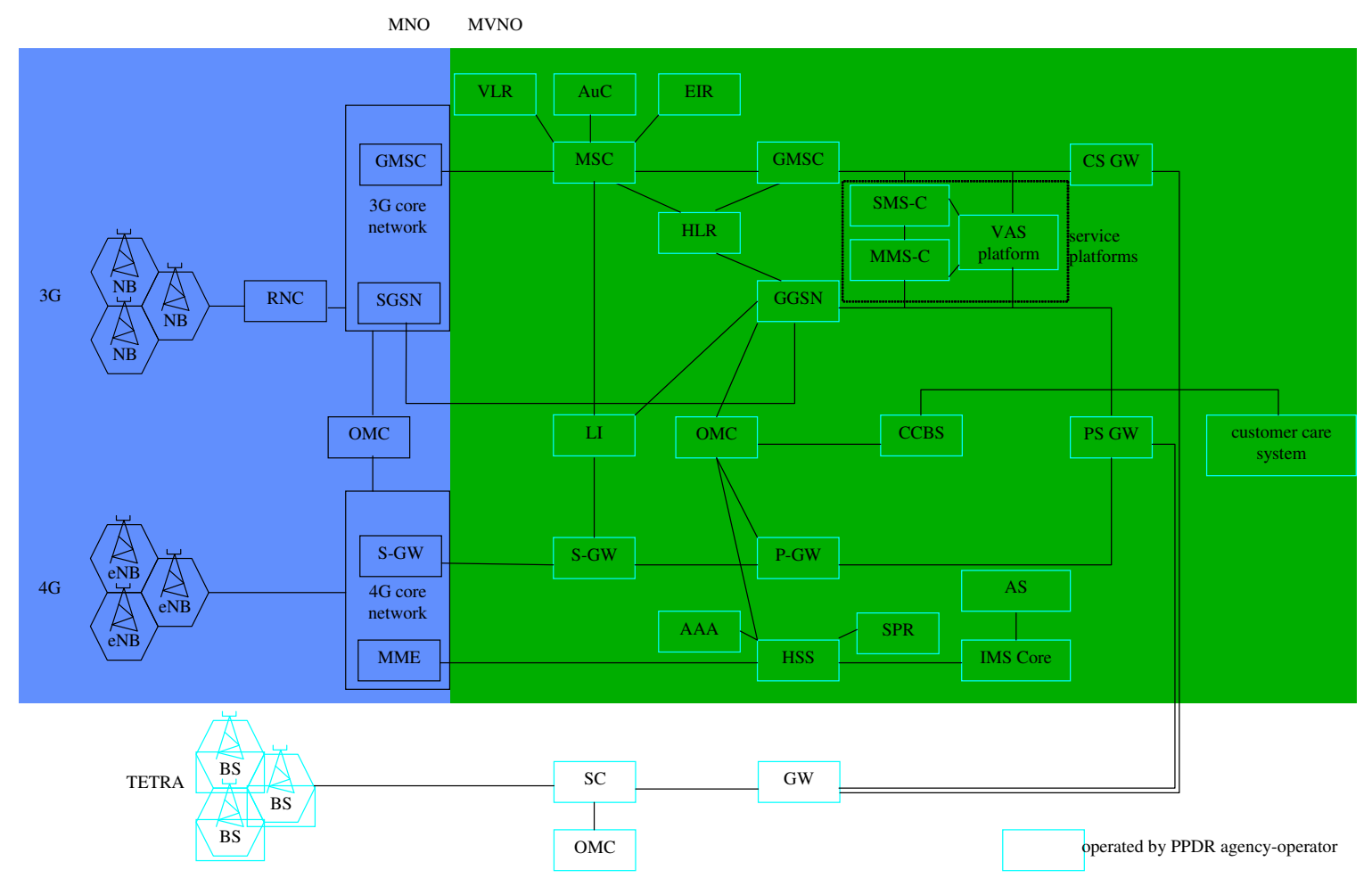

Figure 1. System architecture when PPDR operator is a Pure MVNO

CMNO's 4G network consists of:

- RAN that composes of:

- evolved NB (eNB),

- core network where the most important components are:

- Mobile Management Entity (MME),

- Serving GateWay (S-GW).

MVNO's 4G core network is composed of:

- S-GW,

- Packet Date Network (PDN) GateWay (P-GW),

- Home Subscriber Server (HSS),

- Authentication, Authorization and Accounting (AAA),

- Subscription Profile Repository (SPR),

- IMS (Internet Protocol Multimedia Subsystem) Core,

- Application Servers (AS).

Moreover, there are some common elements for $3 \mathrm{G}$ and $4 \mathrm{G}$ sub-networks operated by MNO:

- backhaul network,

- backbone network,

- Operation and Maintenance Center (OMC).

At the MVNO site there are also some common elements for $3 \mathrm{G}$ and $4 \mathrm{G}$ sub-networks:

- Lawful Interception (LI),

- OMC,

- Customer Care and Billing System (CCBS),

- Packet Switch GateWay (PS GW) used by 3G PS domain and $4 \mathrm{G}$.

MVNO who is a PPDR agency-operator governs:
- 3G CS and PS core,

- service platforms,

- 3G CS and 3G/4G PS gateways,

- $4 \mathrm{G}$ core,

- provision of services using IMS Core and AS,

- customer care system that allows managing PPDR entities' customers.

In TETRA/TETRAPOL sub-network there are:

- Base Stations (BS),

- Switching Center,

- interoperability GateWay (GW),

- OMC.

Distinction of network elements and processes handled by operators is given in Fig. 2. PPDR Pure MVNO is engaged in:

- O\&M of core network,

- operation of Point of Interconnect (PoI),

- operation of LI,

- operation of different types of register (HLR/VLR, EIR, SPR),

- authentication, authorization and ciphering,

- operation of VAS platform including SMS-C, MMS-C, Internet access, IMS Core and ASs as well as Application Programming Interfaces (API) to service and content providers.

The remaining tasks are done by MNO. It includes operation of:

- RAN, backhaul and backbone, 


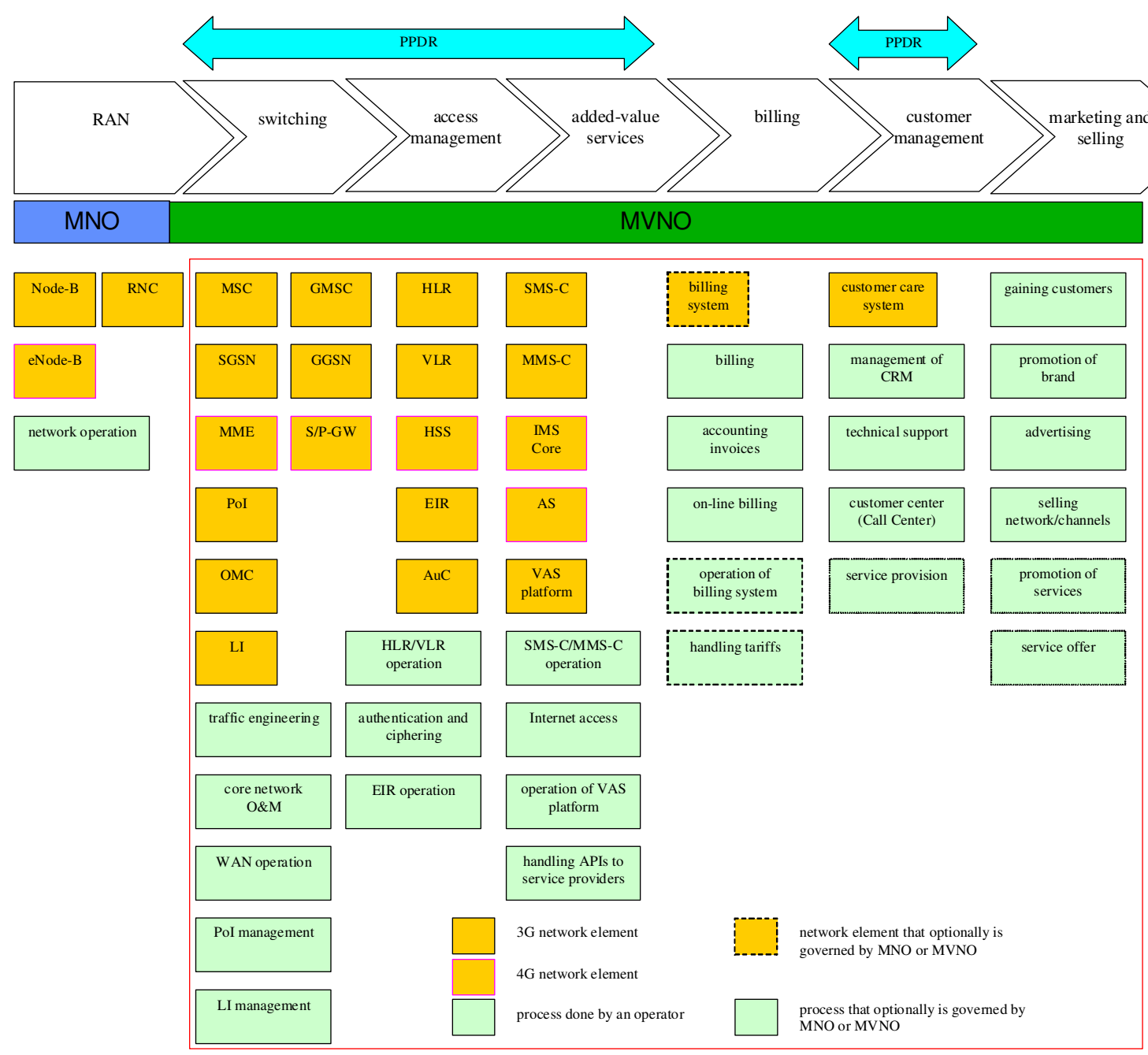

Pure MVNO

Figure 2. Value-added chain for Pure MVNO

- its core network.

Such a system architecture needs reliable interconnection and high QoS. The challenge in such an infrastructure is the provision of QoS based on Service Level Agreement (SLA). For the PPDR organization the quality requirements may be more stringent than those required for a public network. The cost implications to upgrade the mobile network may not be economically viable for a MVNO agreement with the PPDR organization.

However, in this approach there is the potential for PPDR agencies to obtain a level of independence from CMNO. A pure MVNO can ensure higher level of security and can deploy their own services quicker.

Potential sub-options to the presented architecture are hybrid models where the PPDR operator is:

- MVNO with shared RAN network and MNO with dedicated RAN network; as MNO the PPDR operator has own frequency carriers within relevant spectrum resources available nationwide; the own RAN infrastructure is built by PPDR agencies in some parts of a country to cover:

- the most important/risky areas,

- areas where there is no coverage from CMNOs used as hosts for virtualization;

- MVNO with shared RAN network but this sharing concerns all RAN components except frequency band; PPDR organisations have own frequency carriers within relevant spectrum resources available nationwide. These frequency channels are allocated to host's eNBs.

In all cases the MVNO agreement can be reached with one or more MNO host operators to increase coverage, availability and capacity. Advantages and disadvantages of this approach are summarized in Table III. In the above two cases a PPDR operator is partly MVNO so such a model affects both CAPEX and OPEX.

Regarding spectrum issues, this approach assumes that the 3G/LTE network operate in the bands licensed to the CMNO so the bands depend on the operator and the country. The solution also remains feasible for future spectrum bands dedi- 
Table III

ADVANTAGES AND DIS ADVANTAGES OF SHARING RAN BY PURE MVNO TO PROVIDE BROADBAND SERVICES TO PPDR AGENCIES

\begin{tabular}{|l|l|}
\hline \multicolumn{1}{|c|}{ Advantages } & \multicolumn{1}{c|}{ Disadvantages } \\
\hline \hline Moderate CAPEX & $\begin{array}{l}\text { Some boundaries on the transfer } \\
\text { volume can be established by } \\
\text { CMNO }\end{array}$ \\
\hline $\begin{array}{l}\text { Quicker deployment than building } \\
\text { the network by own }\end{array}$ & Moderate OPEX \\
\hline $\begin{array}{l}\text { Mission-critical voice services are } \\
\text { secured using PMR network }\end{array}$ & $\begin{array}{l}\text { Low network availability during } \\
\text { crisis events due to congestion in } \\
\text { CMNO's infrastructure }\end{array}$ \\
\hline $\begin{array}{l}\text { In non critical cases RAN can be } \\
\text { used for voice and data to } \\
\text { increase overall capacity }\end{array}$ & \begin{tabular}{l} 
Coverage depends on CMNO \\
\hline $\begin{array}{l}\text { Security can be hardened using } \\
\text { own core network }\end{array}$
\end{tabular} \\
\hline Easier to deploy new services & $\begin{array}{l}\text { No priority of services for PPDR } \\
\text { agencies }\end{array}$ \\
\hline
\end{tabular}

cated for PPDR (e.g. proposed $700 \mathrm{MHz}$ bands for harmonized Public Safety use). Moreover commercial operators may be interested in getting access to new PPDR spectrum that would be designated for PPDR use as the highest priority use but it could be available for commercial operation when not used by PPDR users. Such an approach needs, however, further investigation and strict control including immediate preemption of commercial users when PPDR spectrum is needed for designated users.

In the planning phase of this solution one has to take into consideration the potential for outages of the broadband network due to congestion during crisis events. It affects voice, message and data which are vital.

\section{UPGRADE OF PPDR NETWORKS TOWARDS BROADBAND SERVICES}

Due to many factors the migration path to broadband PPDR networks will consist of a few steps. Nationwide TETRA/TETRAPOL networks were expensive but expenditures for broadband ones will be even greater because more base stations are required to cover the same area if higher frequency bands are used. On the other hand, some infrastructure elements (e.g. masts, server rooms, etc.) are available and can be re-used. Many other infrastructure elements will need to be upgraded (e.g. backhaul network) or even replaced (e.g. base stations). Moreover, this evolution has to be harmonized with other considerations such as LTE standardization to ensure equipment / networks support the requirements for Mission Critical Communications and with the release of frequency bands to be re-allocated for PPDR communication.

It seems that this evolution of PPDR networks will be based on several intermediate business approaches. The other assumption is that TETRA networks remain in use due to their maturity and great resiliency. However, the other option is to turn off the TETRA networks as soon as the broadband networks are operational to reduce overall costs (e.g., energy consumption and updates) borne by PPDR organizations. As shown in Fig. 3, 3G/4G broadband services provided by commercial MNOs can be used by PPDR agencies now.
The evolution path can begin when 3GPP Release 13 is standardized and equipment is available to support Group Communication service and Mission Critical Push-To-Talk (PTT) one. Equipment might become commercially available after 2018It could happen after 2018.

The first step is for the PPDR organization to set up as a MVNO on a number of $4 \mathrm{G}$ networks to improve availability and reliability of services. This can be time consuming because many contracts have to be negotiated and signed as in the case of roaming.

The second step can begin when the $700 \mathrm{MHz}$ band is released for PPDR mobile purposes. How this band will be arranged is still under international discussion by EU [12][13], International Telecommunication Union (ITU) and European Conference of Postal and Telecommunications Administrations (CEPT) [14]-[16], as well as by national regulation authorities [17]. In [12] a proposal was made to defer coprimary allocation of spectrum below the $700 \mathrm{MHz}$ band to the mobile service until 2030 in order to give political and business reassurance for terrestrial television broadcasting and Program Making and Special Events (PMSE) applications. After 2025 a discussion can be reopened how this band can be allocated to inform stakeholders in advance before the deadline for safeguards of 2030. Now it seems more clear that further protection of the Ultra High Frequency (UHF) band for the production and ubiquitous delivery of audiovisual content is not needed after that deadline and mobile broadband services will be able to use it. At the national level the release of radio channel allocations is another issue. The expiry dates of existing broadcasting licenses in the UHF band are 2023 and 2026 for $48.5 \%$ and $72.8 \%$ of countries, respectively. That is why the second step of the migration has to be delayed. In this step the PPDR organization becomes an MNO with its base stations and frequencies deployed in hot-spots in limited geographic areas but it still maintains the status quo as a MVNO because the coverage of its own RAN is limited.

Finally, the PPDR MNO can operate dedicated radio channels in both commercial and own RAN networks. In this third step a close collaboration with at least one CMNO is still needed because it supports the access to its RAN.

In all steps the PPDR body can additionally reach national roaming contract(s) with $\mathrm{CMNO}$ (s) in order to ameliorate QoS, network coverage, and service availability. Such a CMNO is not the host for the MVNO but collaboration rules remain very similar.

In Fig. 3 mobility vs. capacity is shown for different technologies including TETRA, Universal Mobile Telephony System (UMTS), High Speed Packet Access (HSPA) and LTE/LTE-Advanced. The demand for higher speed services will limit the number of users that can be supported. The instant throughput also depends on the distance of the mobile from the base station and is controlled with adaptation of transmission parameters to fit to propagation conditions, e.g., Adaptive Modulation and Coding (ACM) mechanisms. 


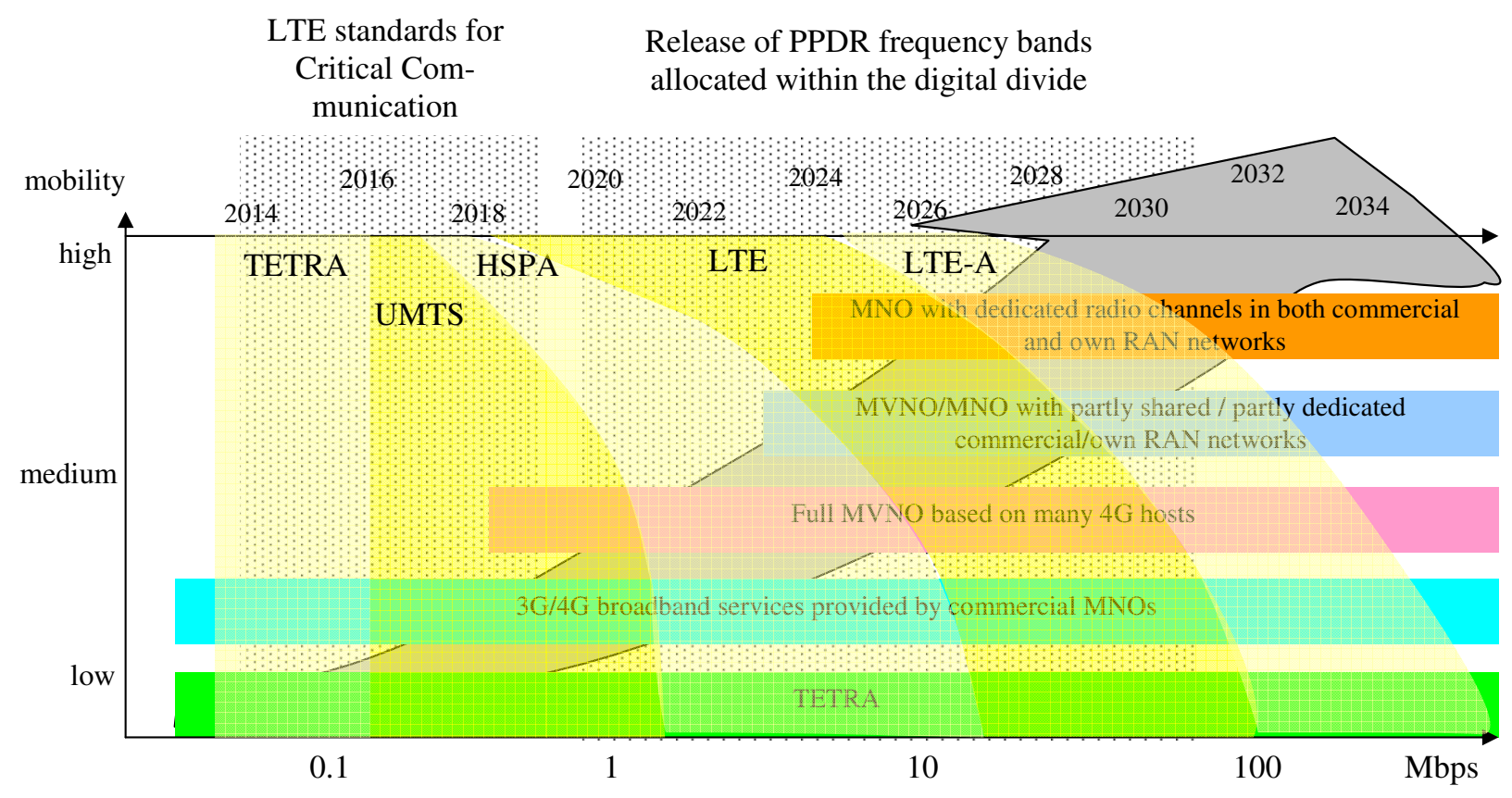

Figure 3. Migration path to broadband PPDR networks (LTE-A - LTE-Advanced).

\section{EVALUATION OF EXPENDITURES}

The expenditures of such a migration process presented in Sec. IV were evaluated using a software tool [8] developed to compare different business models. The tool supports topdown and bottom-up analysis and takes into account a number of considerations including technical, financial-economic and organizational aspects.

In this example use case we have estimated the migration costs of a nationwide network for the energy sector in Poland. Needs defined by the energy sector that are related to the bearer services in the communication scenarios (cf. Sec. II) are presented in Table IV. In the case of major incidents the voice service is the key requirement as it provides instantaneous and the fastest way for personnel to exchange information. In the energy sector's network there are 111000 terminals in operation and $50 \%$ of them will be replaced with LTE terminals during the migration phase up to 2025 . Within step 2

Table IV

COMMUNICATION NEEDS MATRIX FOR ENERGY SECTOR IN MAJOR INCIDENTS

\begin{tabular}{|c|c|c|c|c|c|}
\hline $\begin{array}{l}\text { Communi- } \\
\text { cation } \\
\text { scenario }\end{array}$ & Voice & $\begin{array}{l}\text { NB } \\
\text { data }\end{array}$ & $\begin{array}{l}\text { BB } \\
\text { data }\end{array}$ & Video & Repeater \\
\hline$\overline{\mathrm{A}}$ & 0 & (1) & 0 & 0 & $\odot$ \\
\hline B & 0 & $\odot$ & 0 & 0 & $\odot$ \\
\hline $\mathrm{C}$ & 0 & 0 & 0 & 0 & $\odot$ \\
\hline $\bar{D}$ & (1) & 0 & 0 & 0 & 0 \\
\hline $\mathrm{E}$ & $\odot$ & $\odot$ & 0 & 0 & 0 \\
\hline $\bar{F}$ & 0 & 0 & 0 & 0 & $\odot$ \\
\hline $\bar{G}$ & $\odot$ & $\odot$ & 0 & 0 & $\odot$ \\
\hline $\mathrm{H}$ & 0 & $\odot$ & 0 & 0 & $\odot$ \\
\hline
\end{tabular}

Notation of needs: $\odot$ High, Medium, $\odot$ Low, $\bigcirc$ Not required and step 3 the energy sector will build 1600 eNBs. CAPEX and OPEX of each step along the migration path is shown in Fig. 4. The greatest CAPEX is in step 3 because the greatest number of base stations is built in this period. The energy sector has to pay license costs for reservation of radio channels in the 700 $\mathrm{MHz}$ band as well. The greatest OPEX is observed in step 1 due to expenditures related to operation and maintenance of the whole infrastructure delivered by the CMNO host.

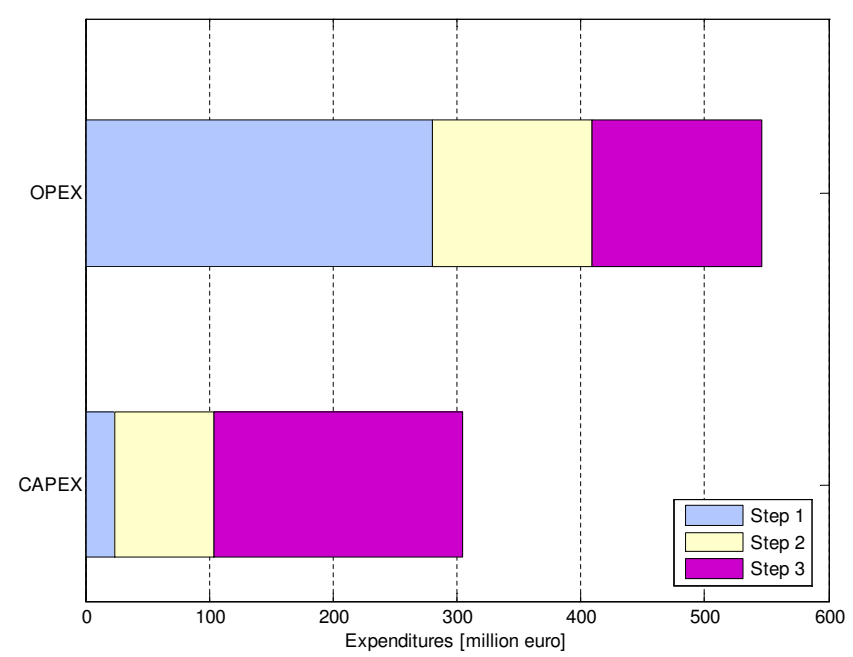

Figure 4. CAPEX and OPEX breakdown for all steps in the migration path

\section{CONCLUSION}

In this paper we have presented several issues related to future migration of PPDR communication networks to broadband. PPDR organizations would like to benefit from the current evolution in mobile technologies to use broadband 
services. One can envisage that future PPDR networks will be based on LTE (LTE-Advanced) technology but existing narrowband networks (e.g. TETRA) will still be required due to their maturity and proven provision of mission critical voice communications. For example, German BOSNet network based on TETRA standard is planned to be fully deployed this year. TETRA networks will be also built by the energy sector's companies in Poland. Nevertheless, LTE technology has to be significantly developed in order to meet the requirements of Public safety organizations and work is currently ongoing within the 3rd Generation Partnership Project (3GPP) as well as by TETRA and Critical Communications Association (TCCA). The main benefit from the deployment of LTE broadband networks is the provision of video. In the UK a dialogue with manufacturers began last year in Great Britain to inform the replacement process of the current TETRA-based Airwave network. The plan is for a commercially operated new 4G LTE-based mission-critical network for public-safety and other governmental organizations.

One of the crucial aspects of the migration path is selecting a business model that meets the requirements of a broadband network defined by the PPDR organizations. The provision of a new own network can involve considerable expenditure and hybrid approaches can significantly reduce costs. However models based on being a MVNO require detailed planning, negotiations and acceptable SLAs to both parties. Other options where the PPDR organizations are a MVNO and also roll-out a limited own network to ensure coverage and/or capacity in specific geograhic areas may be attractive if suitable spectrum can be made available.

There may be the potential to use the $700 \mathrm{MHz}$ band but its use depends on existing reservations in each country. Also the re-allocation of the spectrum may take several years and will vary by country. Therefore, the process of evolution towards broadband networks will certainly take a few years.

\section{ACKNOWLEDGMENT}

H. G. gratefully acknowledges Jacek Jarzina from TELECOM and Sławomir Fryska from YAGI-FRYSKA for interesting and valuable discussions on deployments of PMR networks.

\section{REFERENCES}

[1] C. Lucente, "700 $\mathrm{MHz}$ spectrum requirements for Canadian public safety interoperable mobile broadband data communications," Martello Defence Security Consultants Inc., 2011.

[2] "Comments of the City of New York in the matter of additional comment sought on public safety, homeland security, and cyber security elements of the National Broadband Plan (NBP) Public Notice no. 8," 2009.

[3] "User requirements and spectrum needs for future European broadband PPDR systems (Wide Area Networks)," ECC Report 199, 2013.

[4] J. S. Marcus, J. Burns, V. Jervis, R. Wählen, K. R. Carter, I. Philbeck, and P. Vary, "PPDR Spectrum Harmonisation in Germany, Europe and Globally,” WIK-Consult, Report prepared for BMWI Germany, 2010.

[5] "Updates Broadband Speed Benchmark to $25 \mathrm{Mbps}$ to Reflect Consumer Demand, Advances in Technology," News, Federal Communications Commission, 2015.

[6] "User Requirement Specification; Mission Critical Broadband Communication Requirements," ETSI TR 102 022-1, 2012.

[7] CEPT ECC Radio Spectrum for Public Protection and Disaster Relief (PPDR) working group, FM49(14)008rev1 Network Types part (Draft ECC Report B)

[8] H. Gierszal; K. Pawlina, P. Tyczka, K. Romanowski D. Lavaux, and C. Katsigiannis, "Business models and multi-domain analysis for acquiring broadband PPDR systems," 10th IEEE International Conference on Wireless and Mobile Computing, Networking and Communications (WiMob), 8-10 October 2014, Larnaca, Cyprus, pp. 334-340, DOI 10.1109/WiMOB.2014.6962191

[9] T. Bassayiannis, Mobile Virtual Network Operator (MVNO), MBIT Thesis, Athens Information Technology, 2008.

[10] S. Forge, R. Horvitz, C. Blackman, "A study on the use of commercial mobile networks and equipment for "mission-critical" high-speed broadband communications in specific sectors," SMART 2013-0016, SCF Associates Ltd., Stakeholder Workshop, 30 April 2014.

[11] J. Vinkvist, T. Pesonen, and M. Peltola, "Finland's 5 steps to critical broadband," RadioResource International, 4/2014.

[12] P. Lamy, "Results of the work of the high level group on the future use of the UHF band (470-790 MHz)," Report to the European Commission, 2014.

[13] "Draft RSPG Opinion on a long-term strategy on the future use of the UHF band (470-790 MHz) in the European Union," EC RSPG 14585(rev1), 2014.

[14] "Harmonized technical conditions for mobile/fixed communications networks (MFCN) in the band 694-790 $\mathrm{MHz}$ including a paired frequency arrangement (Frequency Division Duplex 2x30 MHz) and an optional unpaired frequency arrangement (Supplemental Downlink)," ECC Decision $(15) 01,2015$

[15] "Report A from CEPT to the European Commission in response to the Mandate: "To develop harmonized technical conditions for the 694$790 \mathrm{MHz}$ ('700 MHz') frequency band in the EU for the provision of wireless broadband and other uses in support of EU spectrum policy objectives". Provisional lower band edge subject to precise definition within the scope of this Mandate", 2014.

[16] "Long Term Vision for the UHF broadcasting band," ECC Report 224, 2014.

[17] M. J. Grzybkowski, "Systemy PPDR w przestrzeni widmowej II dywidendy cyfrowej" (PPDR systems in the view of II digital divide), Przegląd Telekomunikacyjny (Telecommunications Review), no. 4/2015, pp. 477-480, DOI: 10.15199/59.2015.4.92 [in Polish]. 